\title{
Determination of LME sensitivity of zinc-coated steels based on the programmable deformation cracking test
}

\author{
M. Meyerdierks ${ }^{1}$ (D) $\cdot$ M. Zinke ${ }^{1}$ (D) S. Jüttner ${ }^{1}$ (D) $\cdot$ E. Biro ${ }^{2}$ (D)
}

Received: 1 December 2020 / Accepted: 30 August 2021 / Published online: 6 October 2021

(c) The Author(s) 2021, corrected publication 2022

\begin{abstract}
The current work presents a new test method to evaluate liquid metal embrittlement (LME) susceptibility of zinc-coated steels in arc processes under application-oriented conditions. The procedure is based on the programmable deformation cracking test (PVR test). The PVR test is a variation of a controlled tensile test for hot cracking investigations in arc welding processes. Two dual-phase steels (DP600, DP980) and five transformation-induced plasticity steels (TRIP690, TRIP700, TRIP700, TRIP1100, TRIP1200) were used. The investigations showed that comparable thermo-mechanical loading conditions can be guaranteed for materials of different sheet thicknesses in the PVR test through a targeted adjustment of the heat input per unit length of weld. Furthermore, it was shown that the critical deformation rate $v_{c r}$ (used for assessing hot cracking susceptibility) may also be used to assess the LME susceptibility of a particular steel. Furthermore, another LME susceptibility parameter, the relative reduction in load-bearing ability $\Delta \Sigma$ could be derived, which may be used to understand how LME cracking affects materials' mechanical and fracture properties.
\end{abstract}

Keywords PVR test $\cdot$ Hot cracking $\cdot$ Liquid metal embrittlement $\cdot$ Liquid metal-assisted cracking $\cdot$ LME $\cdot$ LMAC $\cdot$ Arc welding $\cdot$ Zinc coating $\cdot$ AHSS steel $\cdot$ LME test method

\section{Introduction}

Deterioration of solid metallic materials by liquid metals has been known by various terms. In the literature this phenomenon is often referred to as liquid metal embrittlement (LME) or liquid metal-assisted cracking (LMAC) [1]. However it is

Recommended for publication by Commission II - Arc Welding and Filler Metals

M. Meyerdierks

martin.meyerdierks@ovgu.de

M. Zinke

manuela.zinke@ovgu.de

S. Jüttner

sven.juettner@ovgu.de

E. Biro

elliot.biro@uwaterloo.ca

1 Institute of Materials and Joining Technology (IWF), Otto von Guericke University Magdeburg, Universitaetsplatz 2, 39106, Magdeburg, Germany

2 Faculty of Engineering, Mechanical and Mechatronics Engineering, University of Waterloo, 200 University Avenue West, E5 3004, Waterloo, Ontario N2L 3G1, Canada called, during LME, solid metal exposed to tensile stresses is deteriorated by a liquid metal, which leads to brittle intergranular cracking [2-4]. In the literature, there are four requirements for LME to occur, which are as follows: tensile stress (either residual or externally applied), a solid metal, a liquid metal in contact with the solid metal, and the environmental conditions (e.g., exposure time, temperature) [5-17]. Such conditions can be found in various technical areas of metal-processing industry, e.g., in hot-dip galvanizing, resistance spot welding, arc welding, and arc brazing. Central questions from material manufacturers and users concern the susceptibility of a material to LME under manufacturing conditions and how critical the LME cracks are in the subsequent product life cycle.

In the literature, there exist different test procedures to evaluate and investigate the LME behavior of materials, whereby a distinction must be made between processdependent and process-independent procedures. Processdependent methods aim to generate the real, complex conditions of the manufacturing process as precisely as possible, while process-independent methods aim to generate individual influencing quantities as precisely as possible. Thermo-mechanical testing (Gleeble) is an example of a process-independent method for the LME investigation 
[12]. In the area of hot-dip galvanizing, Mendala [18] developed a susceptibility test where a sample loaded in tension is exposed in a liquid zinc bath. In the area of resistance spot welding, there are varieties of different test setups with different objectives, such as the targeted, provoked generation of cracks to investigate the mechanism of LME cracks or the focus on assessing the LME susceptibility of different materials.

Classifications of the susceptibility to LME cracking, such as the one from Bhattacharya [4], were created on the basis of Gleeble and resistance spot welding testing. However, it is unknown whether this insight may be transferred to arc welding and brazing applications as the stress-state, and the heating and cooling rates of the welded material differs in arc and resistance spot welding processes. In the area of arc welding and brazing, limited methods have been investigated to understand the LME behavior of zinc-coated automotive steels. Biro et al. [19] developed a method to invoke LME during arc welding and brazing using a self-restrained sample to load the tested sample, which was able to differentiate the LME susceptibility of various materials. Likewise, Bruscato [20] also used a self-restrained sample to evaluate the LME susceptibility of austenitic steels. These test setups enable the generation of LME cracks and the definition of LMEcritical conditions, but the options for targeted variation of the influencing quantities remain limited. Razmpoosh et al. [21] used a method similar to the externally stress coupons during laser beam welding to provoke LME. Driessen et al. [22] have derived a procedure based on the programmable deformation cracking test (german: Programmierter-Verformungs-RissTest or PVR for short), standardized in [23-25]). As the PVR externally loads samples while they are arc welded, it should allow testing LME susceptibility under arc welding conditions; however, currently no studies have done this.

To test materials' hot cracking susceptibility, there are numerous methodologies. These include Gleeble testing $[24,25]$, testing of self-restrained samples [19, 20, 26], and testing of externally stressed flat tensile tests (PVR test [24, 25]). As discussed previously, the Gleeble [12] and the selfrestrained [20] tests have also shown the capable of measuring LME susceptibility. Since the test specimen in the PVR test is subjected to a combined load of temperature, stress, and strain, it can be assumed that this test is also suitable for investigating the LME susceptibility. In analogy to the determination of the critical deformation rate for hot cracks, it stands to reason that there also exists a critical deformation rate for LME crack formation. However, ISO/TR 17641-3 [24] only recommends a certain specimen geometry with a specimen thickness of $10 \mathrm{~mm}$ and Merkblatt DVS 1004-2 [25] only shows an example for a sheet metal thickness of $2 \mathrm{~mm}$. The sheet metal thicknesses in the automotive industry typically vary in the range of $0.8-3 \mathrm{~mm}$. The specific thickness used depends on the required strength of the component. Therefore, not all materials are available in the same sheet metal thickness for a material comparison. One example can be found in lightweight construction concepts, in which weight savings are achieved through substitution with materials of higher strength. If, in the PVR test, the same welding parameters are used for different sheet thicknesses, different thermo-mechanical conditions result. Therefore, a direct comparison of the materials with regard to their susceptibility to cracking (hot cracking and LME cracking) is not possible. Therefore, it is necessary to adjust the welding parameters depending on the sheet thickness. The current study will resolve these issues. Specifically, it will:

- Investigate the potential of the PVR test to assess the LME behavior of zinc-coated automotive steels (transferability of the assessment quantity $v_{c r}$ (critical deformation rate), deriving further assessment options).

- Determine the thermo-mechanical conditions that will result in LME as a function of the welding parameters.

- Compare the LME susceptibility of various zinc-coated automotive steels with differing sheet thicknesses.

\section{Materials and methods}

Seven hot dip zinc-coated steels of different strengths were selected for the investigations, including two dual-phase steels (DP) and five transformation-induced plasticity steels (TRIP). Table 1 shows the chemical composition of the base materials. The materials were available in different sheet thicknesses $t_{\text {material }}$ ranging from $1.20 t o 1.75 \mathrm{~mm}$.
Table 1 Composition in wt $\%$ and sheet thickness of the test materials

\begin{tabular}{lllllllll}
\hline Material & $t_{\text {material }}(\mathrm{mm})$ & $\mathrm{C}$ & $\mathrm{Mn}$ & $\mathrm{Si}$ & $\mathrm{Al}$ & $\mathrm{Cr}$ & $\mathrm{Mo}$ & $\mathrm{Fe}$ \\
\hline DP600 & 1.22 & 0.09 & 1.7 & 0.2 & 0.03 & 0.3 & - & $\mathrm{Bal}$ \\
DP980 & 1.20 & 0.10 & 2.1 & 0.3 & 0.05 & 0.2 & 0.3 & $\mathrm{Bal}$ \\
TRIP690 & 1.20 & 0.20 & 1.7 & 0.4 & 1.31 & - & - & $\mathrm{Bal}$ \\
TRIP700-I & 1.27 & 0.21 & 1.7 & 0.3 & 0.96 & 0.1 & - & $\mathrm{Bal}$ \\
TRIP700-II & 1.75 & 0.20 & 1.8 & 0.3 & 0.96 & 0.1 & - & $\mathrm{Bal}$ \\
TRIP1100 & 1.60 & 0.20 & 2.2 & 1.6 & - & - & - & $\mathrm{Bal}$ \\
TRIP1200 & 1.60 & 0.22 & 2.3 & 1.7 & - & 0.1 & - & Bal \\
\hline
\end{tabular}


Figure 1 shows the used specimen geometry. It is based on the standard test specimens according to [24, 25]. The rolling direction is along the $453 \mathrm{~mm}$ length of the sample.

All samples were tested in as-received (hot dip zinc coated) as well as the uncoated (reference sample stripped of the hot-dip coating) conditions to understand the material cracking performance in the zinc-coated (LME susceptible) and uncoated (Non-LME susceptible) conditions. Both the tests were carried out using the same test conditions. The reference samples were produced by stripping the zinc coating from the as-received material by soaking the materials in a $20 \%$ hydrochloric acid solution mixed with $3.5 \mathrm{~g} / \mathrm{l}$ hexamethylenetetramine, until bubbling stopped [27]. Afterwards, the samples were rinsed in a bath of distilled water and cleaned with ethanol. Before welding, all stripped samples were exposed to the atmosphere for at least $24 h$, to allow any hydrogen absorbed in the stripping process to volatilize. This excludes any influence of the hydrogen on crack formation. The aging time was based on internal investigations, in which after exposure times of different lengths, hydrogen measurements were done using the hot gas extraction method. After an exposure time of $24 h$, no more diffusible hydrogen was measured in the hot gas extraction in any of the stripped samples. After stripping, the uncoated samples were manually ground using 600 grit sandpaper. All samples were cleaned with ethanol previous to the welding.
LME tests carried out using the PVR test, which is a standardized method to assess the susceptibility to hot cracking [24, 25]. In the PVR test, the superposition of a thermal and a mechanical stress takes place. Figure 2 shows an extended schematic description of the PVR test procedure and the expected occurrence of cracking.

The test specimen has a constant cross section over the entire test area. The sample is subjected to a linearly increasing deformation rate $v_{P V R}$, which results in an increasing tensile stress throughout the test. The welding process, which starts at the same time as the tensile process, uses a constant welding speed, $v_{w}$, so as the weld progresses, the deformation rate, $v_{P V R}$, of the local area exposed to the welding heat source will increase. As the deformation rate increases, the tensile stress of the specimen increases, leading to cracking once a critical stress (or deformation rate) has been achieved. After reaching a programmed maximum deformation rate $v_{P V R, \max }$, the test ends and the sample is allowed to cool down without load. Once the sample cools, the location of the first cracks are determined along with the critical longitudinal deformation rate $v_{c r}$ required to initiate cracking, as shown in Eq. (1)

$v_{c r}=\frac{a \bullet L}{v_{w}}$
Fig. 1 Specimen geometry based on the standard test specimens according to $[24,25]$ with marked melt run
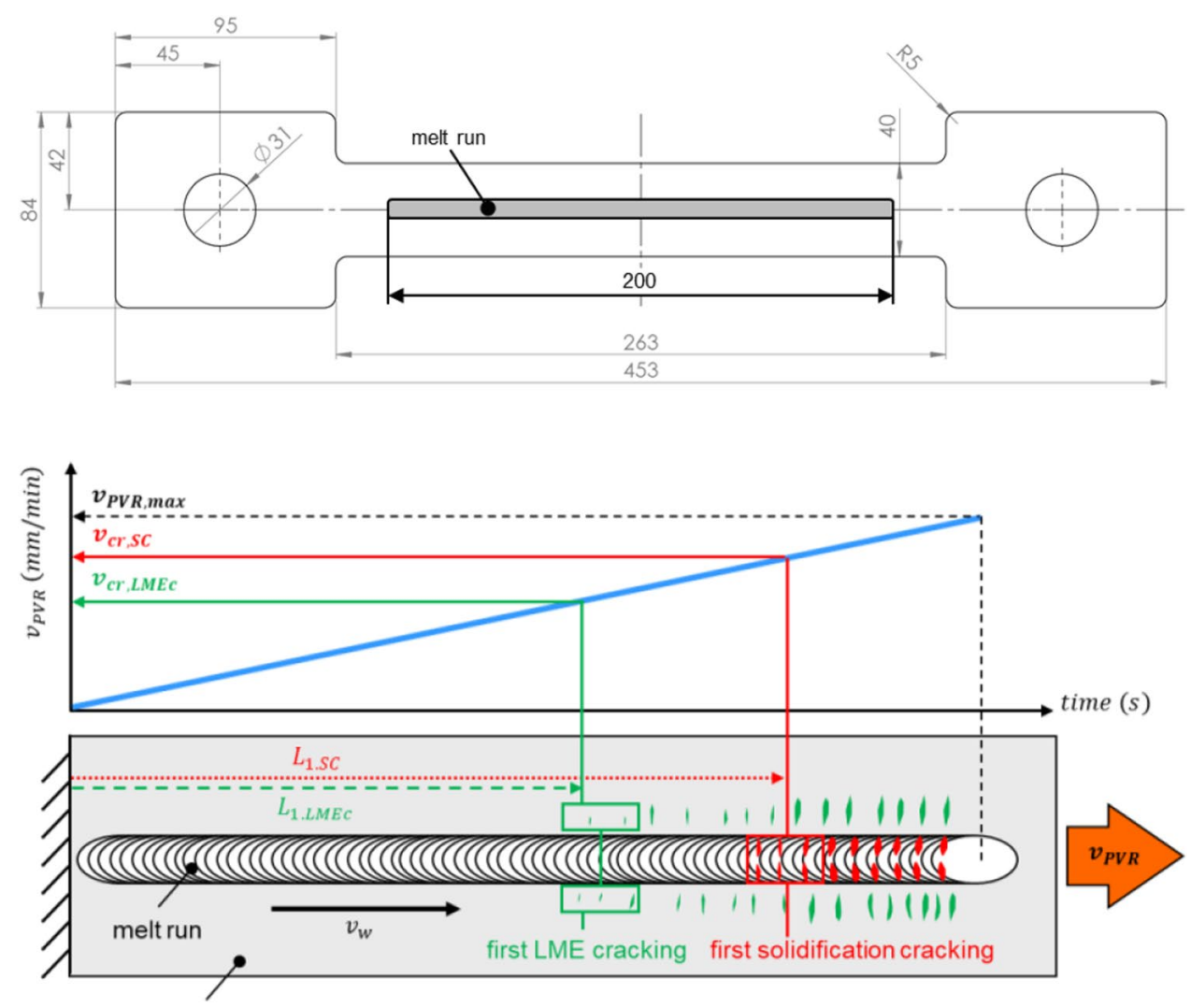

flat tensile specimen
Fig. 2 Extended schematic description of the PVR test procedure and the expected occurrence of cracking in the PVR test for a susceptible test material (LME in the heat affected zone and solidification cracking in the melt run). Derived from the basic scheme according to $[24,25]$ 
where $a$ is defined as tensile acceleration and $L$ is the mean value of the position of the first three cracks. Afterwards, the critical longitudinal deformation rate $v_{c r}$ can be used as a quantitative measurement of the cracking susceptibility. The smaller the critical longitudinal deformation rate, the greater the susceptibility of the material to cracking.

Generally, the hot cracking phenomena can be divided into solidification cracking (SC), liquation cracking (LC), and ductility dip cracking (DDC). In the present investigation, only solidification cracking and LME cracking occurred. During the analysis, the uncoated sample provided the basis for differentiating between the observed cracking phenomena (solidification cracking and LME cracking). Cracking that also occurred on the uncoated material was defined as solidification cracking as LME cracking requires the presence of zinc. Conversely, cracking that only occurred on the hot dip zinc-coated samples could only be LME cracking. By inserting the position of the first solidification cracks $\left(L_{1 . S C}\right)$ or the first LME cracks $\left(L_{1 . L M E c}\right)$ in Eq. (1), the respective critical deformation rate of the solidification cracking $\left(v_{c r, S C}\right)$ or the LME cracking $\left(v_{c r, L M E c}\right)$ was obtained.

The position of the first three cracks (solidification cracks and LME cracks) was determined after the test by means of the dye penetrant test which was carried out in accordance with ISO 3452-1 [28] and microscopic surface examinations at $25 \times$ magnification.

The welding heat source used for all tests was a tungsten inert gas welding arc (TIG arc). Argon was used as shielding gas with a volume flow of $20 \mathrm{l} / \mathrm{min}$. The welding parameters were recorded with a WeldAnalyst from the company HKS Prozesstechnik GmbH.

The tests were divided into 5 test series (see Table 2). In test series 1, all specimens were tested in the hot dip zinccoated state with the same set of parameters. To understand the heat input applied to the material, the applied heat input per unit length of weld $E$ is calculated using Eq. (2)

$E=\frac{U_{w} \bullet I_{w}}{v_{w}}$

where $U_{w}$ is defined as welding voltage, $I_{w}$ as welding current, and $v_{w}$ as welding speed. As all materials differed in sheet thicknesses, the heat input per unit length of weld was adjusted in test series 2 to create a comparable thermomechanical load condition for all test specimens. This was based on the approach of Biro et al. [19]. This resulted in developing a thickness normalized heat input per unit length

Table 2 Test parameters for the test series 1-5

\begin{tabular}{|c|c|c|c|c|c|c|c|c|c|c|c|c|}
\hline Test series & Material & State & $\begin{array}{l}t_{\text {material }} \\
(\mathrm{mm})\end{array}$ & $\begin{array}{l}U_{w} \\
(V)\end{array}$ & $\begin{array}{l}I_{w} \\
(A)\end{array}$ & $\begin{array}{l}v_{w} \\
\left(\frac{\mathrm{cm}}{\min }\right)\end{array}$ & $\begin{array}{l}L_{0} \\
(m m)\end{array}$ & $\begin{array}{l}v_{P V R, \max } \\
\left(\frac{\mathrm{mm}}{\min }\right)\end{array}$ & $\begin{array}{l}E \\
\left(\frac{k J}{m m}\right)\end{array}$ & $\begin{array}{l}\frac{E}{t_{\text {material }}} \\
\left(\frac{k J m m^{-1}}{m m}\right)\end{array}$ & $\begin{array}{l}Q_{\text {base }} \\
\left(\frac{\mathrm{kJmm}^{-1}}{\mathrm{~mm}}\right)\end{array}$ & $\begin{array}{l}E_{\text {norm }} \\
\left(\frac{\mathrm{kJ}}{\mathrm{mm}}\right)\end{array}$ \\
\hline \multirow[t]{7}{*}{1} & DP600 & GI & 1.22 & 9.0 & 52 & 20 & 200 & 50 & 0.140 & 0.115 & \multirow{7}{*}{\multicolumn{2}{|c|}{$\begin{array}{l}\text { In test series } 1 \text {, the heat input per unit } \\
\text { length of weld was not normalized }\end{array}$}} \\
\hline & DP980 & GI & 1.20 & 9.0 & 52 & 20 & 200 & 50 & 0.140 & 0.117 & & \\
\hline & TRIP690 & GI & 1.20 & 9.0 & 52 & 20 & 200 & 50 & 0.140 & 0.117 & & \\
\hline & TRIP700-I & GI & 1.27 & 9.0 & 52 & 20 & 200 & 50 & 0.140 & 0.111 & & \\
\hline & TRIP700-II & GI & 1.75 & 9.0 & 52 & 20 & 200 & 50 & 0.140 & 0.080 & & \\
\hline & TRIP1100 & GI & 1.60 & 9.0 & 52 & 20 & 200 & 50 & 0.140 & 0.088 & & \\
\hline & TRIP1200 & GI & 1.60 & 9.0 & 52 & 20 & 200 & 50 & 0.140 & 0.088 & & \\
\hline \multirow[t]{4}{*}{2} & TRIP700-I & GI & 1.27 & 9.0 & 55 & 20 & 200 & 50 & $\hat{=} E_{\text {norm }}$ & $\hat{=} Q_{\text {base }}$ & 0.117 & 0.149 \\
\hline & TRIP700-I & Uncoated & 1.27 & 9.0 & 55 & 20 & 200 & 50 & $\hat{=} E_{\text {norm }}$ & $\hat{=} Q_{\text {base }}$ & 0.117 & 0.149 \\
\hline & TRIP700-II & Uncoated & 1.75 & 9.0 & 76 & 20 & 200 & 50 & $\hat{=} E_{\text {norm }}$ & $\hat{=} Q_{\text {base }}$ & 0.117 & 0.205 \\
\hline & TRIP700-II & Uncoated & 1.75 & 13.0 & 53 & 20 & 200 & 50 & $\hat{=} E_{\text {norm }}$ & $\hat{=} Q_{\text {base }}$ & 0.117 & 0.205 \\
\hline \multirow[t]{3}{*}{3} & DP600 & GI & 1.22 & 9.0 & 53 & 20 & 200 & 100 & $\hat{=} E_{\text {norm }}$ & $\hat{=} Q_{\text {base }}$ & 0.117 & 0.143 \\
\hline & TRIP700-I & GI & 1.27 & 9.0 & 55 & 20 & 200 & 100 & $\hat{=} E_{\text {norm }}$ & $\hat{=} Q_{\text {base }}$ & 0.117 & 0.149 \\
\hline & TRIP700-II & GI & 1.75 & 9.5 & 72 & 20 & 200 & 100 & $\hat{=} E_{\text {norm }}$ & $\hat{=} Q_{\text {base }}$ & 0.117 & 0.205 \\
\hline \multirow[t]{7}{*}{4} & DP600 & GI & 1.22 & 10.0 & 48 & 20 & 200 & 100 & $\hat{=} E_{\text {norm }}$ & $\hat{=} Q_{\text {base }}$ & 0.117 & 0.143 \\
\hline & DP980 & GI & 1.20 & 10.0 & 47 & 20 & 200 & 100 & $\hat{=} E_{\text {norm }}$ & $\hat{=} Q_{\text {base }}$ & 0.117 & 0.140 \\
\hline & TRIP690 & GI & 1.20 & 10.0 & 47 & 20 & 200 & 100 & $\hat{=} E_{\text {norm }}$ & $\hat{=} Q_{\text {base }}$ & 0.117 & 0.140 \\
\hline & TRIP700-I & GI & 1.27 & 10.0 & 50 & 20 & 200 & 100 & $\hat{=} E_{\text {norm }}$ & $\hat{=} Q_{\text {base }}$ & 0.117 & 0.149 \\
\hline & TRIP700-II & GI & 1.75 & 10.0 & 68 & 20 & 200 & 100 & $\hat{=} E_{\text {norm }}$ & $\hat{=} Q_{\text {base }}$ & 0.117 & 0.205 \\
\hline & TRIP1100 & GI & 1.60 & 10.0 & 62 & 20 & 200 & 100 & $\hat{=} E_{\text {norm }}$ & $\hat{=} Q_{\text {base }}$ & 0.117 & 0.187 \\
\hline & TRIP1200 & GI & 1.60 & 10.0 & 62 & 20 & 200 & 100 & $\hat{=} E_{\text {norm }}$ & $\hat{=} Q_{\text {base }}$ & 0.117 & 0.187 \\
\hline 5 & All & Uncoated & same $\mathrm{p}$ & aramet & er set & ttings as & test sel & ries 4 & & & & \\
\hline
\end{tabular}


of weld, $Q_{b a s e}$, was calculated by dividing $E_{\text {base }}$ by $t_{b a s e}$, as in Eq. 3. The values for $E_{\text {base }}$ and $t_{\text {base }}$ resulted from test series 1 , where a good fusion zone was achieved for the material TRIP690 with a sheet thickness of $1.20 \mathrm{~mm}$ and the heat input per unit length of weld of $0.140 \mathrm{~kJ} / \mathrm{mm}^{-1}$. Therefore, the resulting value for $Q_{\text {base }}$ is a constant for normalizing the heat input per unit length of weld.

$Q_{\text {base }}=\frac{E_{\text {base }}}{t_{\text {base }}}$

Afterwards, $Q_{\text {base }}$ is calculated, the heat input per unit length for the coated material is determined by multiplying $Q_{\text {base }}$ by its respective sheet thickness $t_{\text {material }}$ (see Table 1). This results in the heat input per unit length of weld normalized for the respective sheet thickness $E_{\text {norm }}$, which is required for the comparison (see Eq. (4)).

$E_{\text {norm }}=Q_{\text {base }} \bullet t_{\text {material }}$

Table 2 shows the values resulting from the use of Eq. (4). According to Eq. (2), the heat input per unit length of weld is defined using the three parameters of welding voltage, welding current, and welding speed. This can be used to set the necessary normalized heat input per unit length of weld. To ensure a constant relative movement between the heat source and the specimen, the welding speed was kept constant at $v_{w}=20 \mathrm{~cm} / \mathrm{min}$ for all tests. It is still possible to control the heat input per unit length of weld by changing the welding voltage and the welding current. Both variants were tested in test series 2 .

In addition to the evaluation of the critical deformation rate $v_{c r}$, the test method offers an assessment of how LME cracking affects fracture behavior by comparing the force-time curves of LME-affected and non-LME-affected samples. For this evaluation to be valid test specimens must fails by fracture before the end of the test. To ensure this, the maximum deformation rate was increased to $v_{P V R, \max }=100 \mathrm{~mm} / \mathrm{min}$ in test series 3 .

In test series 4 , the arc voltage was adjusted to $U_{w}=10 \mathrm{~V}$ in favor of a more stable arc, and all test materials were tested under comparable thermo-mechanical loads.

In test series 5, the uncoated reference welding was carried out for each base material under test conditions otherwise identical to test series 4 . Due to the limited scope of the coated materials tested, statistical validation and thus the consideration of the reproducibility of the results could only be realized for the fracture behavior of the DP600-GI, TRIP700-I-GI and TRIP700-II-GI.

Table 2 shows the test parameters for test series $1-5$ in detail.

In addition to evaluating the critical deformation rate, the fracture behavior of the test specimens was evaluated. For this purpose, the recorded force-time curves were converted into engineering stress-time curves. As the change in crosssection in the PVR test was not recorded by measurement, the stresses plotted over time are to be understood as engineering stress, which can be calculated according to Eq. (5) by including the starting cross-section $A_{0}$ which is a function of the respective sheet thickness $t_{\text {material }}$.

$\sigma(t)=\frac{F(t)}{A_{0}\left(t_{\text {material }}\right)}=\frac{F(t)}{t_{\text {material }} \bullet 40 \mathrm{~mm}}$

The assessment of the fracture behavior was used in analogy to the LME Gleeble test evaluation to assess the LME behavior after Béal [12]. By integrating the engineering stress over time, the load-bearing ability of the sample calculated for the states uncoated $\left(\Sigma_{\text {uncoated }}\right)$ and coated $\left(\Sigma_{\text {coated }}\right)$ according to Eq. (6). The integration limits for the loadbearing ability extends from the start of welding to fracture, defined as $t_{\text {fracture }}$.

$\Sigma_{\text {uncoated } / \text { coated }}=\int_{0}^{t_{\text {fracture }}} \sigma_{\text {uncoated } / \text { coated }}(t) d t$

Subsequently, the relationship between load-bearing ability of the coated and uncoated materials was calculated, and the relative reduction of the load-bearing ability $\Delta \Sigma$ was determined according to Eq. (7).

$\Delta \Sigma=\frac{\Sigma_{\text {uncoated }}-\Sigma_{\text {coated }}}{\Sigma_{\text {uncoated }}} \cdot 100 \%$

Finally, based on $\Delta \Sigma$ value, the ability of LME to degrade the fracture behavior of a particular material may be evaluated.

\section{Results and discussion}

\subsection{Cracking phenomena of the test materials in the PVR test}

PVR testing of the materials was carried out. Solidification cracks were detected in all TRIP steels (TRIP690, TRIP700I, TRIP700-II, TRIP1100 and TRIP1200). The DP steels (DP600 and DP980) showed no solidification cracking. Figure $3 \mathrm{a}$ and Fig. $3 \mathrm{~b}$ show an example of the solidification cracking that occurred at the investigated TRIP steels. It may be confirmed that these cracks were indeed solidification cracks and not LME as cracks were seen in the fusion zone of material that were both in the hot dip zinc coated as well in the uncoated condition.

The occurrence of solidification cracking was used to show that the normalization of the heat input per unit length of weld allows thermo-mechanical load conditions to be compared for all sheet thicknesses (see Sect. 3.3). To show 
Fig. 3 Solidification cracking in the fusion zone at TRIP700GI-1.75-E.norm (I)-v100. (a) Cracking indications in the dye penetrant test. (b) Microscope surface image of the first solidification cracking

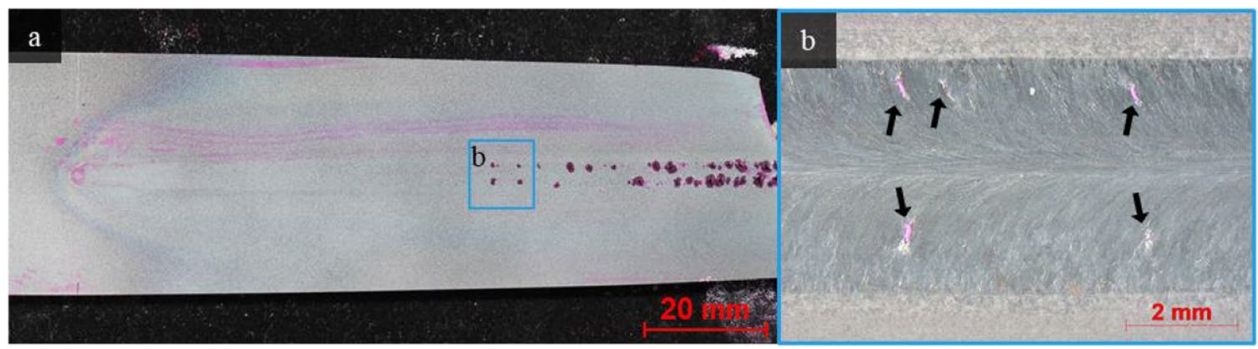

the usability of this method for various materials, it was sufficient to use the TRIP700-I and TRIP700-II. Therefore, the susceptibility to solidification cracking for the materials TRIP690, TRIP1100, and TRIP1200 was not investigated more in detail.

LME cracking, in the area of the heat affected zone (HAZ) near the fusion zone, only occurred in TRIP1100-GI and TRIP1200-GI. As stated previously, it was determined that these cracks were caused by LME as cracking only occurred in materials that were in the hot dip zinc-coated condition.

It was observed that the TRIP1100-GI tends to form frequent and shallow LME cracks. Conversely, the LME cracks in the TRIP1200-GI were much deeper; however, fewer cracks were seen than in the tests on the
TRIP1100-GI. Figure 4a and Fig. 4b show that LME cracking occurred in the TRIP1100-GI and Fig. 4c and Fig. 4d the LME cracking in the TRIP1200-GI. Compared with the investigations by Wintjes et al. [29], the PVR test showed comparable results with regard to the tendency for LME cracking occurrence. In the resistance spot welding test, the TRIP690-GI and DP980-GI showed no or only a few cracks, while the TRIP1100-GI and TRIP1200-GI showed a high level of LME cracking occurrence [29].

In all cases, the LME cracks were perpendicular to the direction of the external tensile load and the direction of welding. The reason for this is the generated tensile stress in the welding direction due to the linearly increasing deformation rate in the PVR test. This agrees the
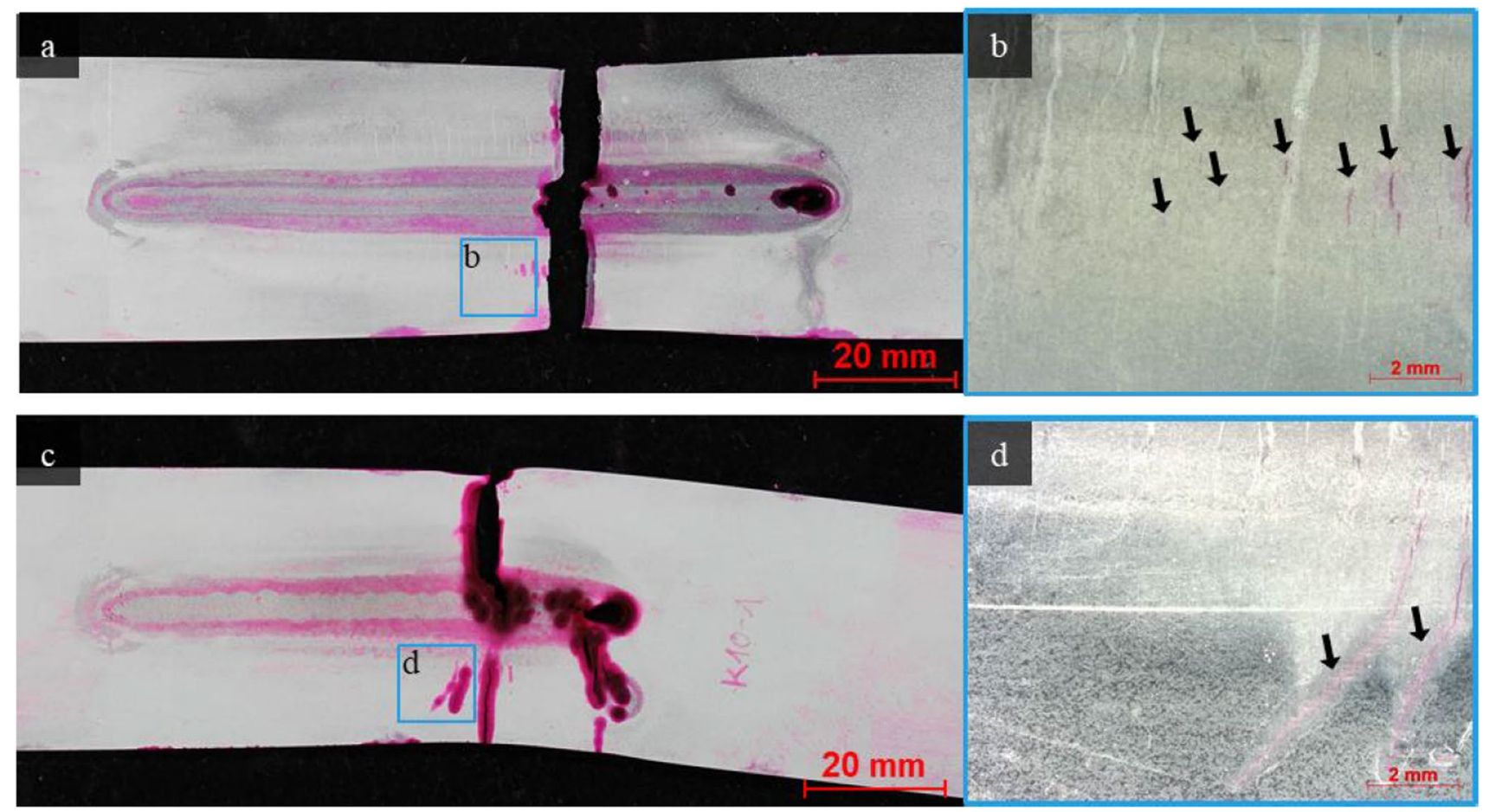

Fig. 4 LME cracking detection using the dye penetrant test. (a-b) First LME cracking in the HAZ of TRIP1100-GI-1.60-E.norm (I) v100. (c-d) First LME cracking in the HAZ of TRIP1200-GI-1.60-E. norm (I)_v100. $(\mathbf{a}+\mathbf{c})$ Overview picture of the dye penetrant test. (b+d) Microscope surface image of the first LME cracking. (d) Cracks go through the entire thickness of the sheet metal and are also open at the bottom (see Fig. 10b) 
observations where LME cracks were created using an externally applied force $[12,30]$.

\subsection{Evaluation of the thermo-mechanical system when comparing different sheet thicknesses in the PVR test}

In test series 1, all materials were tested in the hot dip zinccoated condition using the same welding parameters. As all the materials have various thicknesses, the force-time curves resulting from these experiments could not be directly compared. Figure $5 \mathrm{a}$ shows that the test material TRIP700-GI-1.75 $(t=1.75 \mathrm{~mm})$, which has a minimum tensile strength of $R_{m, \min }=690 \mathrm{MPa}$ at room temperature, showed higher maximum forces in the test than the material DP980-GI-1.20 $(t=1.20 \mathrm{~mm})$, which has a minimum tensile strength of $R_{m, \min }=980 \mathrm{MPa}$ at room temperature. In addition, the material TRIP690-GI-1.20 $(t=1.20 \mathrm{~mm})$ and TRIP700-GI-1.27 $(t=1.27 \mathrm{~mm})$, with similar chemical

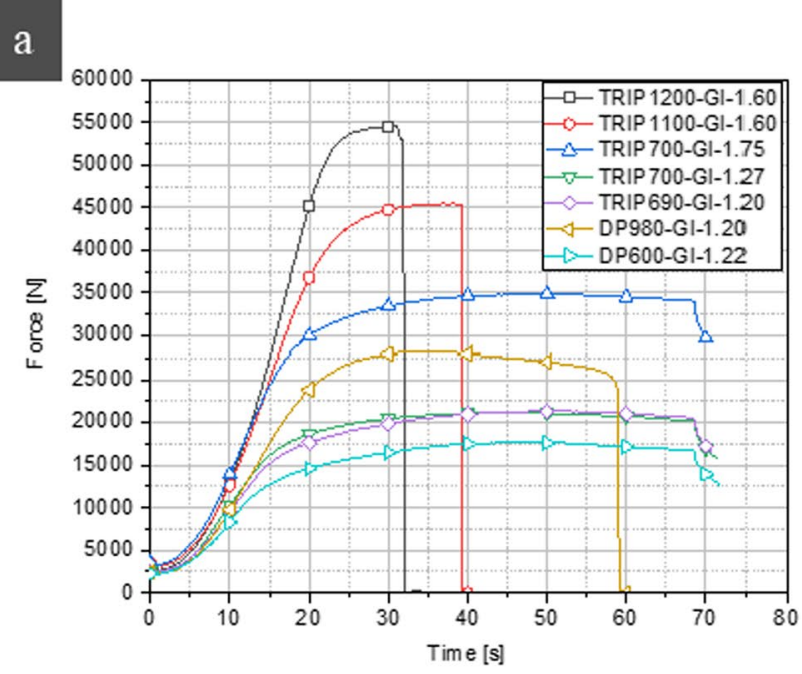

Fig. 5 Evaluation of the thermo-mechanical load on the test specimens over the test period in the PVR test. Interpretation of results without and with consideration of the sheet thickness differences. (a) composition, had a lower force response throughout the test than the TRIP700-GI-1.75. This behavior can initially be explained by the differences in sheet thickness. However, before a comparison can take place, the force must be converted into the engineering stress using Eq. (5) to eliminate the influence of the sheet thickness. Figure $5 \mathrm{~b}$ shows the resulting engineering stress-time diagram.

Calculating and ordering the materials with respect to the failure stress matched correlated with the expected strength order when accounting for the material strength values at ambient temperature. However, the engineering stress-time curves of the TRIP700-GI-1.27 and TRIP700-GI-1.75, despite having the same minimum tensile strength at room temperature and almost identical chemical composition, still had a large variation in failure stress under thermal influence (see Table $3, R_{m, T}$ ). This difference in failure stress was due to the identical welding parameters used for series 1 , which resulted in the heat input per unit length of weld being identical for all materials (see Table 2). All materials

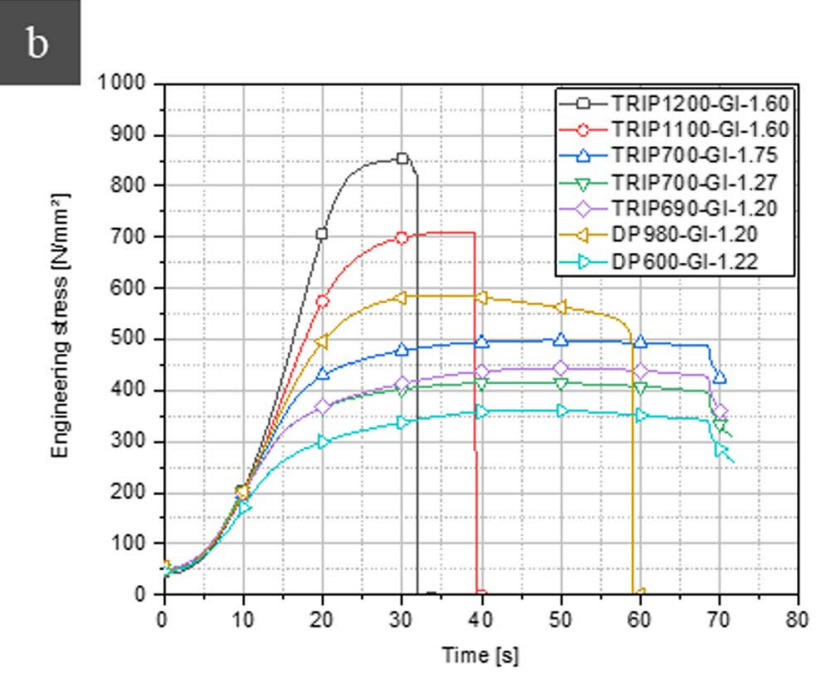

Representation in the form of force-time curve. (b) Representation in the form of engineering stress-time curve
Table 3 Comparison of the minimum tensile strengths of the base materials at room temperature and under thermomechanical load from test series 1 (without normalization of the heat input per unit length of weld) and from test series 4 (with normalization of the heat input per unit length of weld)

\begin{tabular}{lllllll}
\hline Material & $\begin{array}{l}t_{\text {material }} \\
(\mathrm{mm})\end{array}$ & $\begin{array}{l}R_{m, \text { min }, R T} \\
\left(\mathrm{~N} / \mathrm{mm}^{2}\right)\end{array}$ & $\begin{array}{l}R_{m, T} \\
\left(\mathrm{~N} / \mathrm{mm}^{2}\right)\end{array}$ & $\begin{array}{l}\Delta R_{m} \\
(\%)\end{array}$ & $\begin{array}{l}R_{m, T, E \text {.norm }} \\
\left(\mathrm{N} / \mathrm{mm}^{2}\right)\end{array}$ & $\begin{array}{l}\Delta R_{m, \text { E.norm }} \\
(\%)\end{array}$ \\
\hline DP600 & 1.22 & $590^{*}$ & 361 & 39 & 370 & 37 \\
TRIP690 & 1.20 & $690^{*}$ & 444 & 36 & 431 & 38 \\
TRIP700-I & 1.27 & $690^{*}$ & 416 & 40 & 408 & 41 \\
TRIP700-II & 1.75 & $690^{*}$ & 498 & 28 & 436 & 37 \\
DP980 & 1.20 & $980^{*}$ & 586 & 40 & 578 & 41 \\
TRIP1100 & 1.60 & $1080^{* *}$ & 711 & 34 & 594 & 45 \\
TRIP1200 & 1.60 & $1180^{* *}$ & 853 & 28 & 753 & 36 \\
\hline
\end{tabular}

*Values according to [31]; ** Estimated values according to [31] 
were welded with a welding voltage of $U_{w}=9 \mathrm{~V}$, a welding current of $I_{w}=52 \mathrm{~A}$, and a welding speed of $v_{w}=20 \mathrm{~cm} / \mathrm{min}$. However, with increasing sheet thickness, the volume to be heated and the thermal inertia of the welded material increases. Accordingly, as the heat input per unit length of weld was $E=0.140 \mathrm{~kJ} / \mathrm{mm}$, regardless of specimen thickness, the increased temperature field of the thicker specimens (TRIP700-GI-1.75) were narrower and experiences lower peak temperatures than the thinner specimens (TRIP700GI-1.27). Under these test conditions, a comparison of the materials is not possible. For materials to be compared, it must be ensured that a comparable thermo-mechanical state is similar for all test specimens in the test. The fact that this was not true for test series 1 was confirmed when the susceptibility to solidification cracking for the various materials were compared (see Sect. 3.3). Table 3 compares the minimum values of the tensile strength of the base materials at room temperature $R_{m, \min , R T}$ and under the thermal influence in the PVR test $R_{m, T}$ (without normalization of the heat input per unit length of weld) and $R_{m, T, E . n o r m}$ (with normalization of the heat input per unit length of weld). The values for $R_{m, T}$ correspond to the maxima of the engineering stress-time curves from Fig. $5 \mathrm{~b}$, and the values for $R_{m, T \text {,E.norm }}$ correspond to the maxima of the engineering stress-time curves from Fig. 8b (see Sect. 3.6). For a comparison, the relative reduction in tensile strength due to the thermal load $\Delta R_{m}$ can be calculated for both using Eq. (8).

$\Delta R_{m}=\frac{\mathrm{R}_{m, \min , R T}-R_{m, T /, E . n o r m}}{\mathrm{R}_{m, \min , R T}} \cdot 100 \%$

When considering the TRIP700-GI in the two different sheet thicknesses $t=1.27 \mathrm{~mm}$ and $t=1.75 \mathrm{~mm}$, the comparison shows the influence of the heat input per unit length of weld related to the sheet thickness. The difference between the PVR measured tensile strengths of the two materials without adjusting the heat input per unit length of weld is $12 \%$. After normalizing the heat input per unit length of weld (see test series 4 and 5), the relative reduction in tensile strength due to the thermal load is more comparable. That reduced the difference between the PVR-measured strengths of the two TRIP700-GI materials to $4 \%$, as the thermo-mechanical conditions are similar by accounting for thickness when selecting welding parameters. Under these adjusted test conditions, an assessment of the thermosmechanical system can be made.

\subsection{Effect of the normalization of the heat input per unit length of weld on the results in the PVR test}

By normalizing the heat input per unit length of weld according to Eq. (4), test specimens of different sheet thicknesses experience a comparable thermo-mechanical load in the PVR test. Figure 6a shows a comparison of the engineering stress-time curves of the TRIP700 steels of different sheet thicknesses examined in test series 1 and test series 2 before and after the normalization of the heat input per unit length of weld.

According to Eq. (2), the heat input per unit length of weld can be adjusted using the three parameters of welding voltage, welding current, and welding speed. To ensure that the heat source position with respect to the sample was constant for all specimen (as the crosshead speed is changing through the test), welding speed was constant for all tests, and heat input was adjusted by changing the welding current and voltage. Figure $6 \mathrm{~b}$ shows that both adaptations initially provided almost identical thermo-mechanical material behavior with regard to the engineering stress-time curves. However, it was seen that when welding voltage was increased, the energy density of the arc reduced sufficiently that the base material did not melt, as can be seen in Fig. 6d. As the base material was not molten, solidification cracking (SC) did not occur. In contrast, the increasing welding current increased heat input while maintaining energy density, so the maintaining base material being melting, as can be seen in Fig. 6c, and solidification cracking appeared in the fusion zone. Figure 6e shows the comparison of the critical deformation rates for the onset of solidification cracking for the samples from test series 1 (same heat input per unit length of weld) and the samples from test series 2 (normalized heat input per unit length of weld). It shows that normalizing heat input per unit length of weld with respect to the material thickness was able to reproduce the thermomechanical and solidification cracking behavior across samples of various thicknesses. It was also seen that surface condition of the test specimens (uncoated/coated) did not affect the occurrence of solidification cracking. From these results, the subsequent test series was carried out by adjusting the welding current $\left(I_{w}\right)$ to ensure that heat input per unit length of weld was normalized to sheet thickness.

\subsection{Effect of the maximum deformation rate on the thermo-mechanical behavior in the PVR test}

To evaluate how LME cracking affected fracture behavior of the base materials, all tests needed to continue until fracture. Therefore, in test series 3 the necessary maximum deformation rate was investigated. The determined engineering stress-time curves were compared with those from test series 2. Since the materials with lower tensile strength have a higher fracture elongation compared to materials with higher tensile strength, the maximum deformation rate $v_{P V R, \max }$ must be specified using the lower strength materials with higher fracture elongation. For example the DP600 did not fail 


\section{a}
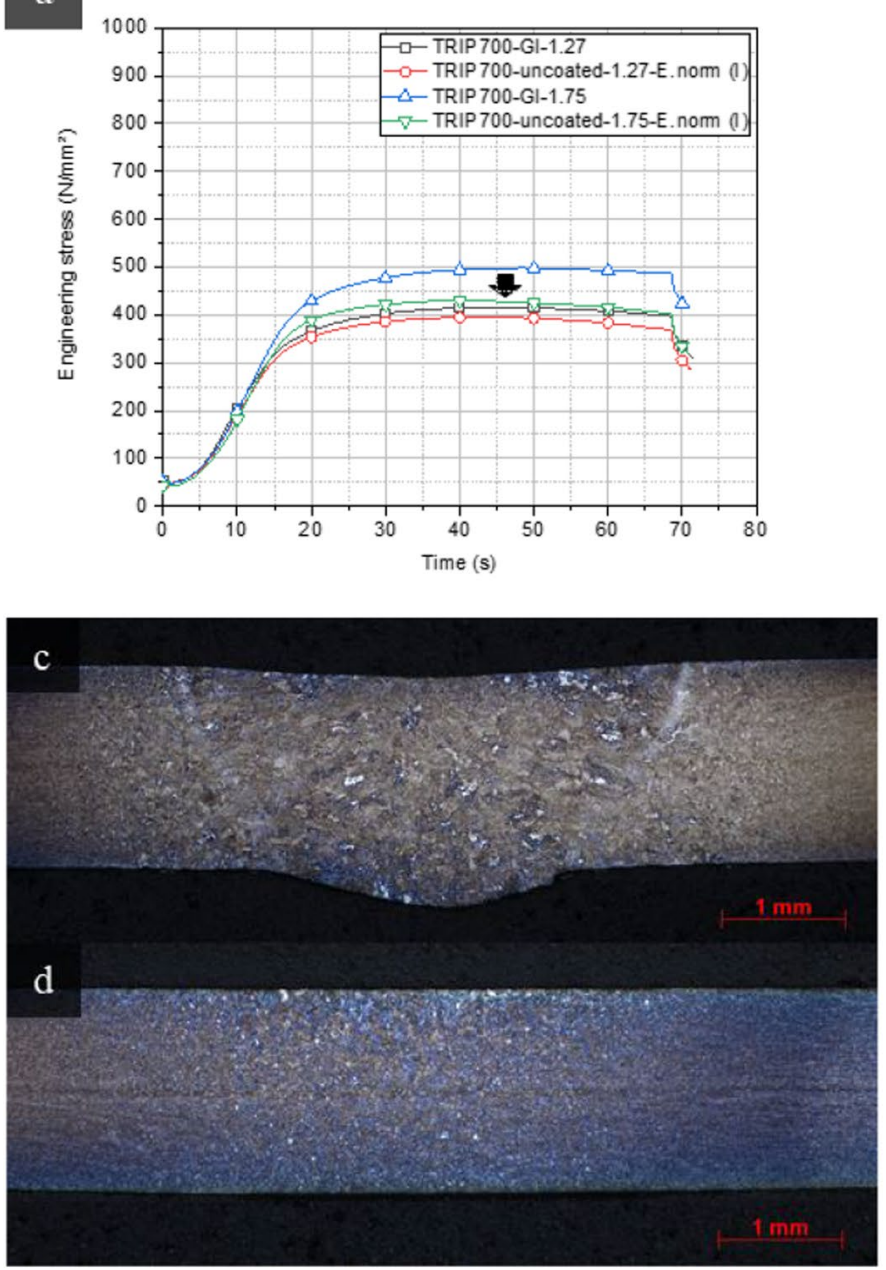

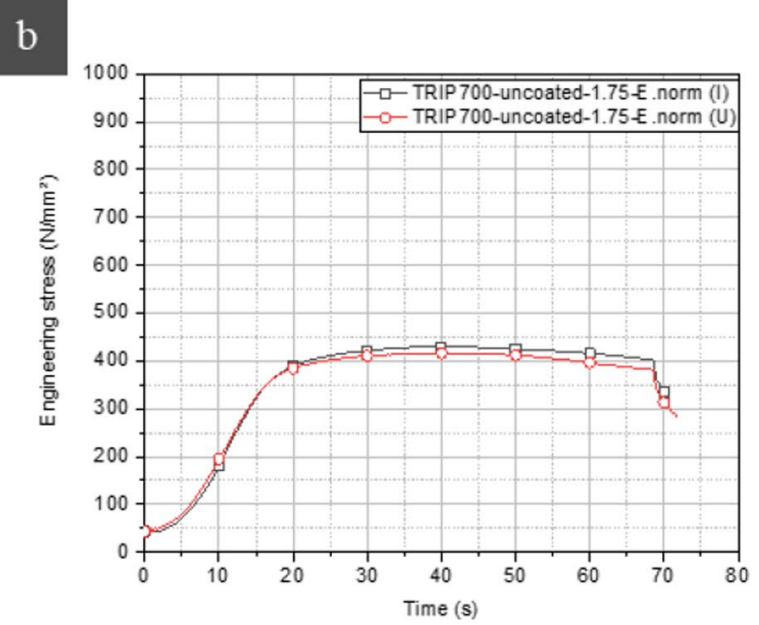

e

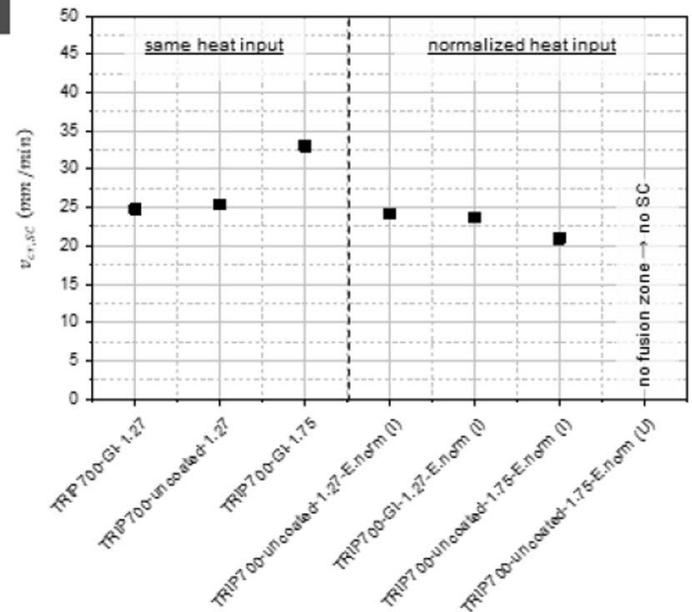

Fig. 6 (a) Comparison of the engineering stress-time curves depending on the sheet thickness and heat input per unit length of weld. (b) Comparison of the engineering stress-time curves of TRIP700II depending on the adjustment of the welding current $\left(I_{w}\right)$ and the welding voltage $\left(U_{w}\right)$. (c) Cross-section of TRIP700-II welded with normalized heat input per unit length of weld by adjusting the weld-

Table 4 Fracture elongation at room temperature for DP600, TRIP700, DP980 according to [31]

\begin{tabular}{llll}
\hline Material & DP600 & TRIP700 & DP980 \\
\hline$A_{80 \mathrm{~mm}, R T}(\%)$ & $\geq 20$ & $\geq 24$ & $\geq 8$ \\
\hline
\end{tabular}

at a maximum deformation rate of $v_{P V R, \max }=50 \mathrm{~mm} / \mathrm{min}$, but the DP980 did (see Fig. 5). Table 4 shows an example of the fracture elongation for three base materials at room temperature.

By increasing the maximum deformation rate to $v_{P V R, \max }=100 \mathrm{~mm} / \mathrm{min}$, specimen failure could be provoked for the base materials DP600, TRIP700-I, and TRIP700-II, as shown in Fig. 7. As a result, a maximum deformation rate ing current $\left(I_{w}\right)$. (d) Cross-section of TRIP700-II welded with normalized heat input per unit length of weld by adjusting the welding voltage $\left(U_{w}\right)$. (e) Susceptibility to solidification cracking of the materials TRIP700-I und TRIP700-II depending on the heat input per unit length of weld

of $v_{P V R, \max }=100 \mathrm{~mm} / \mathrm{min}$ was defined for test series 4 and 5 . This value can be used as a starting value for future investigations of other materials if they have room temperature fracture elongations $\leq 24$ and are exposed to a comparable heat input.

\subsection{Assessment of the LME susceptibility of the test materials using $v_{c r}$}

Assessment material LME susceptibility was carried out in test series 4, analogous to the evaluation method of the hot cracking, by determining the critical deformation rate $v_{c r}$ according to ISO 17641-3 [24] and Merkblatt DVS 1004-2 [25] (see Sect. 2). Only the TRIP1100-GI and TRIP1200-GI 
Fig. 7 Comparison of the engineering stress-time curves in the PVR test depending on the maximum deformation rate for the base materials DP600, TRIP700-I und TRIP700-II

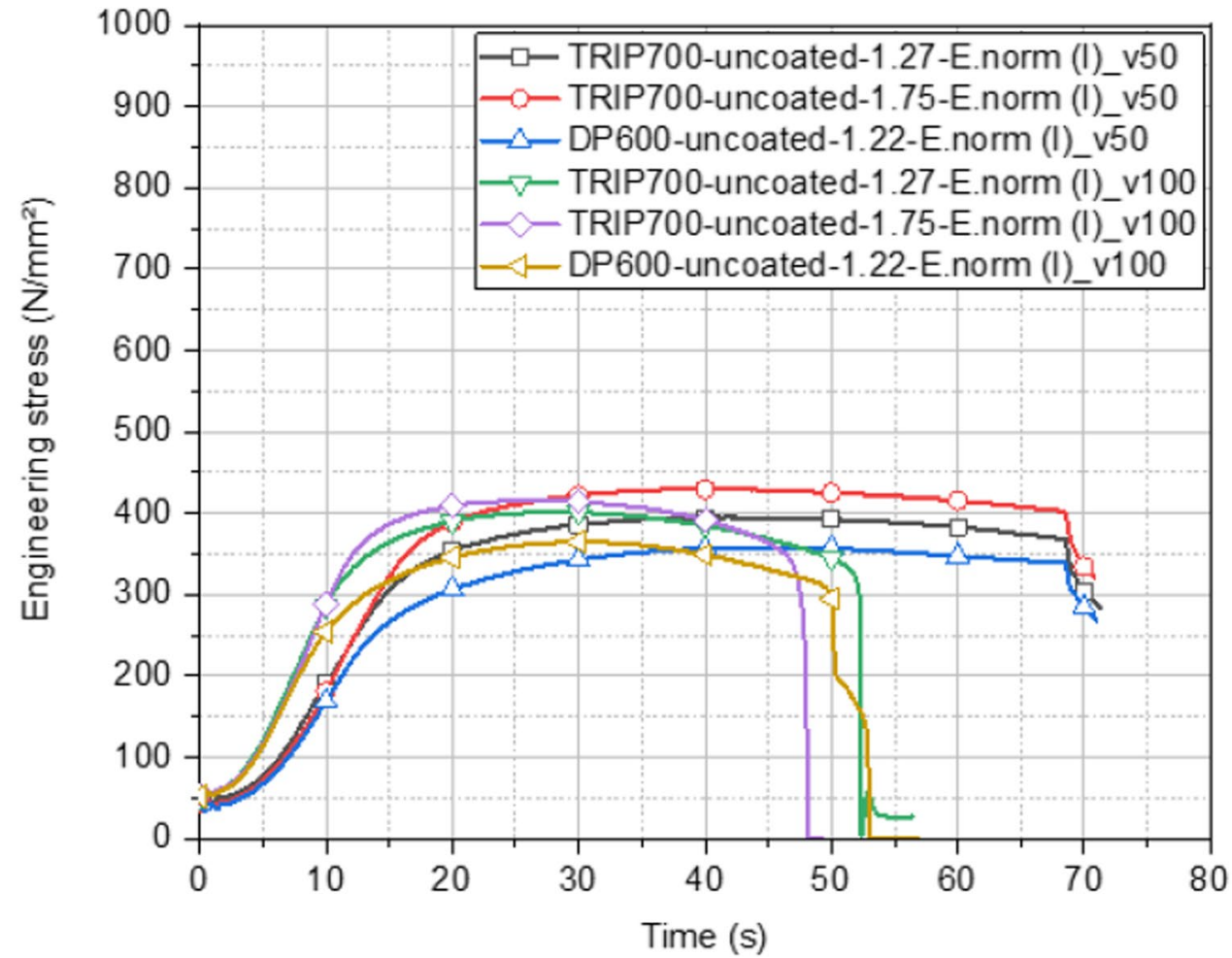

showed LME cracking in the HAZ after the PVR test of the specimens in the hot dip zinc-coated state (see Sect. 3.1). The critical deformation rates for LME of the two materials were calculated according to Eq. (1). TRIP1100-GI-1.60 showed a critical deformation rate of $v_{c r, L M E c}=20 \mathrm{~mm} / \mathrm{min}$ and TRIP1200-GI-1.60 showed a critical deformation rate of $v_{c r, L M E c}=18 \mathrm{~mm} / \mathrm{min}$. Similar to the assessment of hot cracking susceptibility, this shows that the LME susceptibility of both materials are similar. Due to the relatively small difference in values of $v_{c r, L M E c}$ of the two test materials, a definitive statement can only be made after the values have been statistically verified.

\subsection{Assessment of the effect of the LME cracking on the fracture behavior of the test material using $\Delta \Sigma$}

The evaluation of the fracture behavior of a material by means of the PVR test is a new method that has not been used before. To do this, the engineering stress-time curves for the uncoated and coated surface conditions were determined, so that the relative reduction of the load-bearing ability, $\Delta \Sigma$, due to LME could be calculated. This was done in the test series 4 and 5. By choosing the maximum deformation rate $v_{P V R, \max }=100 \mathrm{~mm} / \mathrm{min}$, the necessary specimen fracture was provoked for all specimens before the end of the test, which is shown by a sudden drop in engineering stress-time curves. Figure 8 a shows the engineering stresstime curves of the uncoated reference specimens and Fig. $8 \mathrm{~b}$ that of the hot dip zinc-coated specimens.

It can already be seen that the materials TRIP1100 and TRIP1200 showed an earlier failure due to fracture in the hot dip zinc-coated state than in the uncoated state. While the TRIP1200 breaks shortly after reaching the maximum stress, the TRIP1000 can withstand some plastic deformation before it also fails due to fracture. The behavior is explained by the fact that the extent of the cracks (width, depth) is significantly greater for the TRIP1200 than the TRIP1100 (see Fig. 4b, 4d and Fig. 10b). Larger cracks will impart greater weakening of the load-bearing cross-section and thus further reduced the load-bearing ability of a material. This result coincides with the investigations by DiGiovanni et al. [32] in which was shown that greater crack length have a more significant influence on the failure behavior.

All other test materials showed almost identical engineering stress-time curves when tested in both the coated and uncoated surface conditions. Without cracking in the HAZ, the base material could undergo plastic deformation for a longer period until the specimen finally broke after reaching the material- and temperature-dependent elongation after fracture. Figure 9a shows an example of the engineering stress-time curves for the material TRIP690 in the states uncoated and coated. The failure due to fracture being the same for both states. For this base material, the coating has no effect on the fracture behavior under the present 


\section{a}

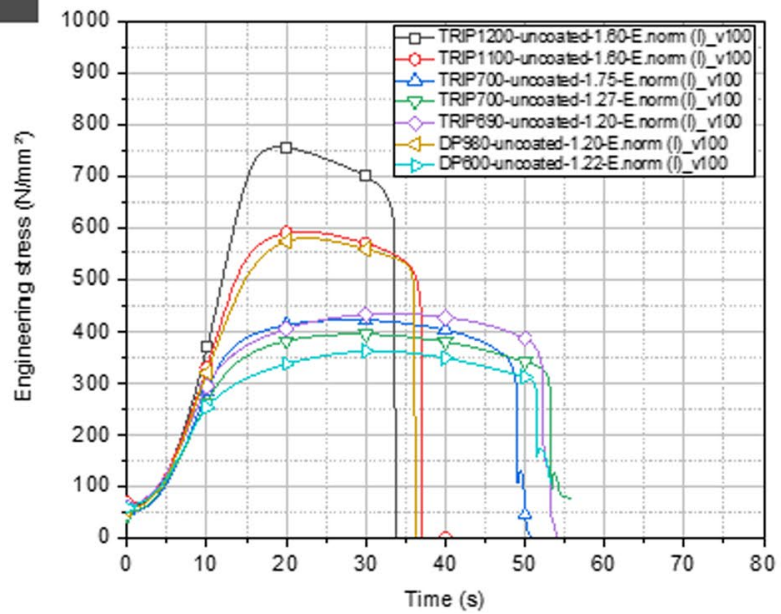

\section{b}

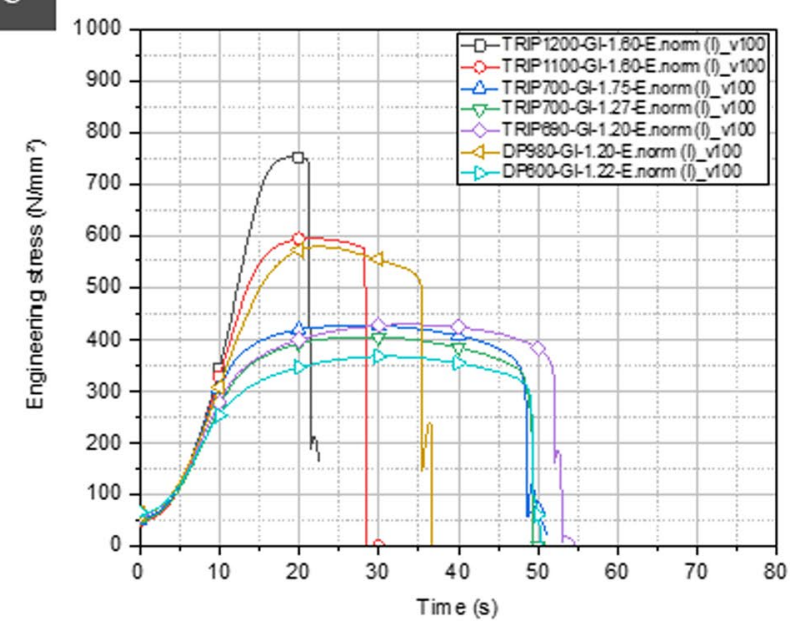

Fig. 8 Comparison of the engineering stress-time curves of the test materials. (a) Test specimen in the uncoated state. (b) Test specimen in the hot dip zinc coated initial state

a

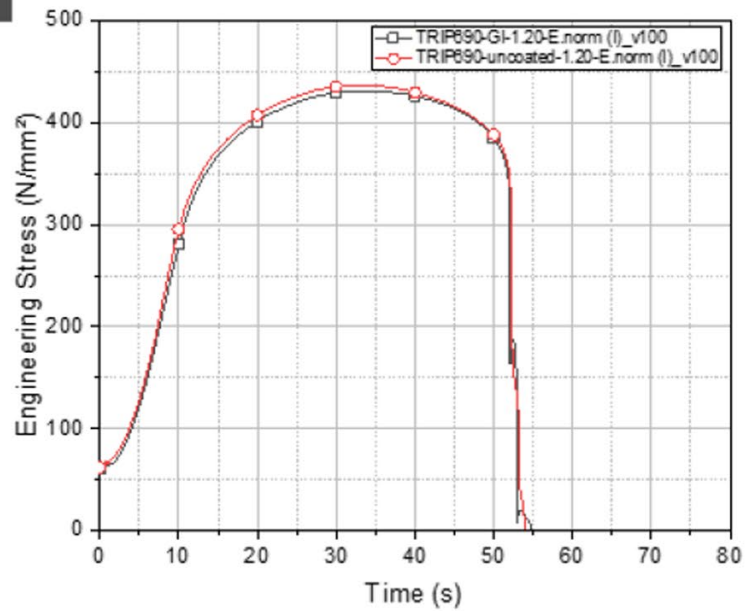

Fig. 9 Superposition of the engineering stress-time curves of a material in hot dip zinc coated and uncoated state. (a) Typical engineering stress-time curves of a material without LME occurrence with the same load-bearing ability up to fracture using the example of

test conditions in the PVR test. Figure 9b shows an example of the engineering stress-time curves for the material TRIP1200. In the presence of zinc, failure occurred much earlier than in the uncoated state.

For a quantitative assessment, in analogy to the Gleeble test according to Béal [12], the load-bearing ability of the material up to fracture $\Sigma_{\text {uncoated }}$ (uncoated state) and $\Sigma_{\text {coated }}$ (coated state) was calculated according to Eq. (6) for all test materials. Then the relative reduction of the load-bearing ability up to fracture $\Delta \Sigma$ was calculated according to Eq. (7) for all tested materials. Figure 10a shows the values for the

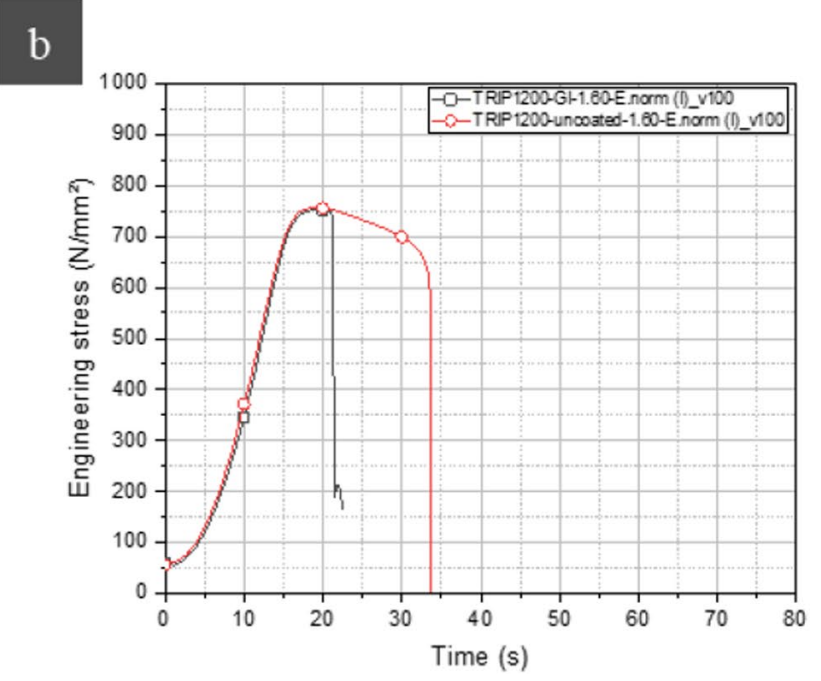

the material TRIP690. (b) Typical engineering stress-time curves of a material with LME occurrence with significantly reduced loadbearing ability in the hot dip zinc coated state until fracture using the example of the TRIP1200

comparative evaluation of the material with regard to the effect of the LME cracks on their fracture behavior. The literature regarding the LME occurrence and the evaluation under application-oriented conditions for arc welding processes is still sparse. There is no clear indication of what is the typical noise in this data, so it cannot be determined what reduction in load-bearing ability indicates that LME affected mechanical properties. To evaluate this question, DP600, TRIP700-I, and TRIP700-II were tested. Three test specimens in both surface conditions (coated and uncoated) were welded, and the standard deviation of the values for 
a

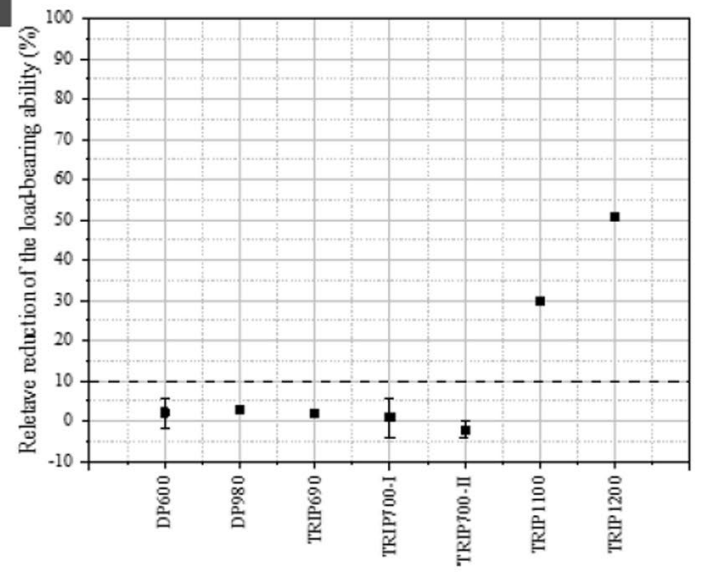

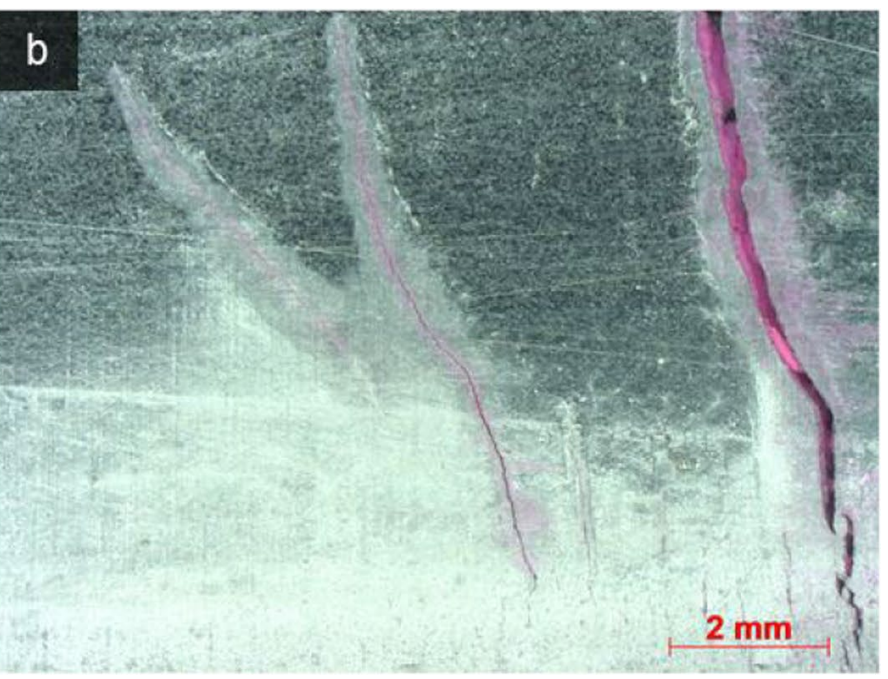

ing indication of the TRIP1200 on the underside of the specimen. Cracks go through the entire sheet metal thickness and are also open at the top (see Fig. 4d)
Fig. 10 (a) Comparison of the relative reduction in the load-bearing ability of the test materials to assess their fracture behavior in the case of LME. (b) Microscope surface image of the first LME crack-
$\Delta \Sigma$ was determined and recorded as a scatter bar, as may be seen in the data for these materials in Fig. 10a. Accordingly, there was good reproducibility and a low scatter of the data in the PVR test of $\pm 5 \%$. From the analysis, a scatter range of $\pm 10 \%$ was defined. If the relative reduction in load-bearing ability is upper $10 \%$, one can consider that LME affected mechanical properties. This value agrees with Béal [12] who measured similar variation when measuring fracture strength of LME affected specimens using a Gleeble.

Using the variation noted above, it was seen that LME did not affect the load-bearing ability of TRIP690 and DP980 (see Fig. 10a). However, the test materials TRIP1100 had a $\Delta \Sigma_{\text {TRIP } 1100}=30 \%$ and TRIP1200 with $\Delta \Sigma_{\text {TRIP } 1200}=51 \%$, which are above the $+10 \%$ limit of the scatter range and show a clear influence of the LME cracking on the fracture behavior.

This consideration makes it possible to assess the fracture behavior of a base material under the influence of LME depending on its coating condition under a thermal-mechanical load. The higher the relative reduction of the load-bearing ability up to fracture, the greater the effect of the LME cracking on the thermal-mechanical fracture behavior of the base material.

\section{Summary}

It was shown that the LME sensitivity (susceptibility and fracture behavior) of materials in arc processes can be examined using the PVR test. The experimental setup enables the generation and control of a critical temperature range by heating using a TIG arc and the external application of a critical mechanical stress by linearly increasing deformation rate in the welding direction. A comprehensive assessment of the LME sensitivity can be made using a small number of samples in the coated and uncoated conditions.

The critical deformation rate $v_{c r, L M E c}$ indicates the LME susceptibility of a material, and it may be used to compare the relative susceptibilities of multiple materials. The lower the critical deformation rate, the more susceptible is the test material under otherwise identical test conditions. It could be shown that the TRIP1100 and the TRIP1200 (in their present condition) have a similar critical deformation rate. Due to the relatively small difference in values of $v_{c r, L M E c}$ of the two test materials, a definitive statement can only be made after the values have been statistically verified.

The evaluation of the fracture behavior of a material by means of the PVR test is a new method that has not been used before. The relative reduction of the load-bearing ability, $\Delta \Sigma$, enables an assessment of the fracture behavior of the base material depending on its coating condition. The higher the relative reduction of the load-bearing ability up to fracture, the greater is the effect of the LME cracking on the thermal-mechanical fracture behavior of the base material. It could be shown that the effect of the LME cracking is significantly greater for the test material TRIP1200-GI (in its present condition) and leads to a greater reduction in deformability and load-bearing ability in comparison to the test material TRIP1100-GI (in its present condition).

The investigations show that a statement about the LME susceptibility of a material alone is not sufficient to be able to characterize its LME behavior. The effects of the cracks should be included in the evaluation. 
The maximum deformation rate of $v_{P V R, \max }=100 \mathrm{~mm} / \mathrm{min}$ which was necessary to promote specimen fracture can be regarded as a guide value for materials with a fracture elongation $\leq 24$ if they are exposed to comparable thermal conditions.

An advantage offered by the testing method is the possibility of a simultaneously evaluation of the susceptibility of the test materials to hot cracking.

It was possible to show that materials of different thicknesses may be compared by designing the welding conditions to induce comparable thermo-mechanical conditions in the materials being compared. This may be done by normalizing the heat input per unit length of weld with respect to material thickness. An adjustment of the welding current is recommended as the manipulating quantity. This was proven by the evaluation of the susceptibility to solidification cracking as well as by the temperature-dependent tensile strength, which were adjusted to a comparable level.

\section{Future work}

For the further validation of the test method, investigations on other materials are planned, for which an assessment of the LME behavior is available from the literature based on Gleeble testing and resistance spot welding tests.

To obtain a better understanding of how the results from the presented arc-based testing method correlate with LME results from resistance spot welding tests an in-depth comparison between the present data with that from Wintjes et al. [29] is planned in follow-up examinations.

Funding Open Access funding enabled and organized by Projekt DEAL.

Data availability Contact the corresponding author.

Code availability Not applicable.

\section{Declarations}

Conflict of interest Not applicable.

Open Access This article is licensed under a Creative Commons Attribution 4.0 International License, which permits use, sharing, adaptation, distribution and reproduction in any medium or format, as long as you give appropriate credit to the original author(s) and the source, provide a link to the Creative Commons licence, and indicate if changes were made. The images or other third party material in this article are included in the article's Creative Commons licence, unless indicated otherwise in a credit line to the material. If material is not included in the article's Creative Commons licence and your intended use is not permitted by statutory regulation or exceeds the permitted use, you will need to obtain permission directly from the copyright holder. To view a copy of this licence, visit http://creativecommons.org/licenses/by/4.0/.

\section{References}

1. International Organization for Standardization (2019) Zinc coatings - Guidelines and recommendations for the protection against corrosion of iron and steel in structures - Part 2: Hot dip galvanizing(14713-2)

2. Kim YG, Kim IJ, Kim JS et al (2014) Evaluation of Surface Crack in Resistance Spot Welds of Zn-Coated Steel. Mater Trans 55:171-175. https://doi.org/10.2320/matertrans.M2013244

3. Cho L, Kang H, Lee C et al (2014) Microstructure of liquid metal embrittlement cracks on $\mathrm{Zn}$-coated 22MnB5 press-hardened steel. Scripta Mater 90-91:25-28. https://doi.org/10.1016/j.scriptamat. 2014.07.008

4. Bhattacharya D (2018) Liquid metal embrittlement during resistance spot welding of $\mathrm{Zn}$-coated high-strength steels. Mater Sci Technol 34:1809-1829. https://doi.org/10.1080/02670836. 2018.1461595

5. Jung G, Woo IS, Suh DW et al (2016) Liquid Zn assisted embrittlement of advanced high strength steels with different microstructures. Met Mater Int 22:187-195. https://doi.org/10.1007/ s12540-016-5579-7

6. Norkett JE, Dickey MD, Miller VM (2021) A review of liquid metal embrittlement: cracking open the disparate mechanisms. Metall Mater Trans A 52:2158-2172. https://doi.org/10.1007/ s11661-021-06256-y

7. Bhattacharya $D$, Cho L, van der Aa E et al (2021) Influence of the starting microstructure of an advanced high strength steel on the characteristics of $\mathrm{Zn}$-Assisted liquid metal embrittlement. Mater Sci Eng, A 804:140391. https://doi.org/10.1016/j.msea. 2020.140391

8. Kang H, Cho L, Lee C et al (2016) Zn Penetration in Liquid Metal Embrittled TWIP Steel. Metall Mater Trans A 47:28852905. https://doi.org/10.1007/s11661-016-3475-X

9. Béal C, Kleber X, Fabregue D et al (2012) Liquid zinc embrittlement of twinning-induced plasticity steel. Scripta Mater 66:1030-1033. https://doi.org/10.1016/j.scriptamat.2011.12. 040

10. Joseph B, Picat M, Barbier F (1999) Liquid metal embrittlement: A state-of-the-art appraisal. Eur Phys J AP 5:19-31. https://doi.org/10.1051/epjap:1999108

11. Nicholas MG, Old CF (1979) Review Liquid Metal Embrittlement. J Mater Sci 14:1-18

12. Béal C (2011) Mechanical behaviour of a new automotive high manganese TWIP steel in the presence of liquid zinc. Dissertation, INSA de Lyon. HAL Id: tel-00679521

13. Kinstler TJ (2004) Current Knowledge of the Cracking of Steels During Galvanizing: A Synthesis of the Available Technical Literature and Collective Experience for the American Institute of Steel Construction. http://www.aisc.org/Content/ContentGro ups/Engineering_and_Research/Research1/Final

14. Benet MHK (ed) (1986) Failure Analysis and Prevention. Metals Handbook, 9th edn., vol 11

15. Boyer RR (ed) (1985) Metallography and Microstructures. Metals Handbook, 9th edn., vol 9

16. Shunk FA, Warke WR (1974) Specifity as an aspect of LME. Scripta Metallurgica 519-526. https://doi.org/10.1016/00369748(74)90062-3

17. James MN (2009) Designing against LMAC in galvanised steel structures. Eng Fai Anal:1051-1061. https://doi.org/10.1016/j. engfailanal.2008.05.019

18. Mendala J (2012) Liquid metal embrittlement of steel with galvanized coatings. IOP Conf Ser.: Mater Sci Eng 35. https://doi. org/10.1088/1757-899X/35/1/012002 
19. Biro E, Jiang C, Hunt J (2010) LME and Hot Cracking Sensitivity of AHSS during Gas Metal Arc Welding and Brazing. Sheet Metal Welding Conference XIV

20. Bruscato RM (1992) Liquid metal embrittlement of austenitic stainless steel when welded to galvanized steel. Weld J 71:455-459

21. Razmpoosh MH, Macwan A, Biro E et al (2018) Liquid metal embrittlement in laser beam welding of $\mathrm{Zn}$-coated $22 \mathrm{MnB} 5$ steel. Mater Des 155:375-383. https://doi.org/10.1016/j.matdes.2018.05.065

22. Driessen J, Ohse P, Nestler F et al. (2014) Prüfung der Risssensibilität eines metallischen Werkstoffes(10 2014109 398.4)

23. International Organization for Standardization (2004) Destructive tests on welds in metallic materials - Hot cracking tests for weldments - Arc welding processes - Part 1: General 24.160.40(17641-1)

24. International Organization for Standardization (2005) Destructive tests on welds in metallic materials - Hot cracking tests for weldments - Arc welding processes - Part 3: Externally loaded tests 25.160.40(17641-3)

25. DVS Verband - Arbeitsgruppe Q 4 "Prüfen von Schweißungen" (2019) Heißrissprüfverfahren mit fremdbeanspruchten Proben(DVS 1004-2)

26. International Organization for Standardization (2015) Destructive tests on welds in metallic materials - Hot cracking tests for weldments - Arc welding processes - Part 2: Self-restraint tests 25.160.40(17641-2)

27. International Organization for Standardization (2020) Metallic coatings - Hot dip galvanized coatings on ferrous materials - Gravimetric determination of the mass per unit area 25.220.40(1460)

28. International Organization for Standardization (2013) Nondestructive testing - Penetrant testing - Part 1: General principles(3452-1)

29. Wintjes E, DiGiovanni C, He L et al (2019) Quantifying the link between crack distribution and resistance spot weld strength reduction in liquid metal embrittlement susceptible steels. Welding in the World 63:807-814. https://doi.org/10.1007/ s40194-019-00712-5

30. Razmpoosh MH, Biro E, Chen DL et al (2018) Liquid metal embrittlement in laser lap joining of TWIP and medium-manganese TRIP steel: The role of stress and grain boundaries. Mater Charact 145:627-633. https://doi.org/10.1016/j.matchar.2018.09. 018

31. Verband der Automobilindustrie e.V. (2016) Flacherzeugnisse aus Stahl zur Kaltumformung(VDA 239-100). https://www.vda. dewww.vda.de

32. DiGiovanni C, Han X, Powell A et al (2019) Experimental and Numerical Analysis of Liquid Metal Embrittlement Crack Location. J of Materi Eng and Perform 28:2045-2052. https://doi.org/ 10.1007/s11665-019-04005-2

Publisher's Note Springer Nature remains neutral with regard to jurisdictional claims in published maps and institutional affiliations. 